\title{
CROSS-CULTURAL APPROACH TO FORMATON A MEDICAL SPECIALIST AT A REGIONAL RUSSIAN UNIVERSITY
}

\author{
Khabibullina Flera Ya. ${ }^{1}$, Ivanova Iraida G. $^{2}$ \\ ${ }^{1}$ Candidate of Pedagogy, Assoc. Prof, Mari State University, RUSSIA, khflora@yandex.ru \\ ${ }^{2}$ Candidate of Philological Sciences, Assoc. Prof., Mari State University, RUSSIA, \\ iraida44@yandex.ru
}

\begin{abstract}
One of the key processes in the development of the world economy at the beginning of the XXI century was globalization - a qualitatively new stage in the development of internationalization of economic life, which entailed the structuring of a new geopolitical space and the change of cultural and civilizational paradigms, making changes in the functioning and interaction of languages and cultures. The imperative of coexistence of different languages and cultures indicates the urgent need to review and change the educational policy, internationalization of education, and the formation of cross-cultural competencies of subjects of the educational space. Academic mobility of students, integration of educational systems and institutions of countries, interstate partnership in the field of professional training of students - a typical landscape of modern educational space. In this regard, special attention should be paid to the specifics of training and education of students in a Russian regional University. In the conditions of intensification and diversification of cross-cultural and cross-linguistic contacts of subjects of the educational process in educational institutions of various types, the issue of their cross-cultural training is being updated. Ability to analyze, compare, compare features between bearers of different cultures as the dominant intercultural approach becomes particularly important in the preparation of the modern professional, given that cross-cultural evaluation can be a professional sphere of business communications with foreign language colleagues. The article focuses on teaching in non-language faculties of the University. In this case, it is advisable to raise and resolve the issue of reorienting the process of their language training to the position of an intercultural approach. It will allow us to realize the modern needs for the transformation of competence models of a University student who masters a language not for the sake of communication, or even for the sake of understanding culture. In this case, language becomes an instrument of dialogue between (professional) cultures and an effective tool for implementing all professional communicative intentions of a specialist associated with interaction with colleagues from another culture, country, or society.

In the context of globalization, the development of the Institute of higher education in Russia cannot be represented without international cooperation. With the introduction of a two - level system of higher professional education in the Russian Federation within the framework of the Bologna process, there is an increase in trends of internationalization-a process of sustainable interaction and mutual influence of national educational systems based on common goals and principles that meet the needs of the world community. The implementation of this direction in higher education is impossible without the formed cross-cultural competencies of participants in the educational process. The article aims to explore the major aspects of forming intercultural competence of future health worker training direction "medicine" on the example of teaching of discipline "Latin language and medical terminology" in Russian regional universities "Mari State University". It is established that the leading aspects in the implementation of the competence approach in the intercultural training of future medical specialists by means of the Latin language are systematic, Dialogic, contextual, terminological and ethical-deontological orientation.
\end{abstract}


The organization of intercultural training is based on the principles of communication, taking into account national and cultural characteristics and intercultural interaction. The principle of communication as a leading methodological principle assumes the organization of the educational process in conditions close to natural for communication. It involves the use of situations of real communication, the organization of active creative activity, the use of collective forms of work, attention to problem situations and creative types of tasks that involve students in common activities.

The accounting principle of national-cultural peculiarities due to the specific multilingual and multicultural students, and having specific experience of training in a natural environment. The principle of intercultural interaction implies such an organization of the educational process, in which the teacher takes into account the national and cultural characteristics of students in terms of intercultural communication with native speakers. The formation of intercultural communication is carried out taking into account the main components: ethnopsychological, due to the mental characteristics of national cultures; behavioral, dictated by the national-cultural specifics of communicative behavior; linguistic, which involves taking into account the national-cultural language content.

Conditions of successful communication depend on several factors: the correct organization of the educational process, contact of the subjects of educational process, availability of teaching materials, equipping classrooms with the necessary technical equipment for presentations and enhance the material security of the faculties competent experts. The effectiveness of the learning process requires a certain socio-cultural training of teachers when working with this contingent of students, which is also necessary, as well as the formation of socio-cultural competence of students. Pedagogical communication is implemented mainly during classroom sessions. Communication between the subjects of the learning process is built using conditional speech situations. The system-forming component of situations is the relationship between communicants, the main factors of which are the role of the participant in the process as a subject of communication and its activities.

Keyword: cross-cultural approach, medical profile, regional Russian University, competence approach, cross-cultural training, Latin language.

\section{INTRODUCTION}

The imperative of coexistence between different languages and cultures points to the urgent need to review and change educational policies, internationalize education, and form intercultural competences of subjects of the educational and educational space. In this regard, special attention should be paid to the specifics of the education and education of students in the Russian regional university. In the context of intensification and diversification of intercultural and inter-linguistic contacts between the subjects of the educational and educational process, the issue of their intercultural training is being updated in educational institutions of various types. An intercultural approach is the most appropriate for student learning, as in a global internationalization, a future professional needs to take into account intercultural differences and cultural commonalities to choose the style, strategies and tactics of communication in cross-cultural business situations. The ability to analyse, compare and compare the characteristics of different cultures as a dominant cross-cultural approach becomes particularly important in the training of a modern professional, considering that the professional sphere of business communication with foreign-speaking and colleagues may be subject to intercultural evaluation. The article emphasizes training of specialists of medical profile in the Russian regional university, as globalization changes the coordinate system and erases the boundaries between the center and the periphery, reinforced by the digital transformation of the modern educational space.

In the context of globalization, the development of the Institute of Higher Regional Education of Russia cannot be represented without international cooperation. With the introduction of a two-tier system of higher vocational education in higher education in the Russian Federation within the framework of the Bologna process, there is an increase in the trends of internationalization - the process of sound interaction and mutual interaction of national educational systems on the basis of common goals and principles that meet the needs of the world community. Implementation of this direction in higher education is impossible without formed intercultural competences of participants of the educational process. The purpose of the article is to study the main aspects of the formation of intercultural competences of the future medical worker in the 
Proceedings of SOCIOINT 2020-7th International Conference on Education and Education of Social Sciences,

direction of training "Medical work" on the example of teaching the discipline "Latin language and medical terminology" in the Russian regional university "Mari State University."

\section{METHODOLOGY AND METHODS}

The study of the problem used competent, intercultural, contextual, axiological approaches. The competency approach enables a student to learn an a virtual workplace that mimics a future professional environment. Such training allows him to adapt to work and learn to apply all types of competences in practice. Context training in Latin is based on the fact that knowledge, skills and skills of operating medical terminology in the relevant situations of quasi-professional activity are given as a means of solving the tasks of the future specialist in the process of projecting both substantive and socio-cultural content on future professional activity, a terminology basis for studying special disciplines, solving real professional situations. The axiological approach characterizes the system of socialization and education of the growing generation and is based on the national educational ideal as the highest pedagogical value. The axiological approach allows the future medical specialist to become the bearer of basic national and moral values. The basic guidelines of this approach are ethical and deontological requirements for the realization of the moral duty of the medical worker to the sick and healthy person, guaranteed by the International Bill of Human Rights, the Constitution and the laws of the country human rights, regardless of his sex, age, race, nationality, social and professional status; Respect for and respect for the human right to receive necessary and adequate medical and social assistance, including psychological and psychiatric care; Respect for the right of the individual: "Do no harm" (Noli nocēre), which remains the main criterion of professionalism of the medical worker.

Both theoretical and empirical methods have been chosen as methods. The first group includes: literature analysis, materials and documents analysis; analysis of basic concepts of research. The second group combines observation and experience of teachers of the university.

\section{LITERATURE REVIEW}

Modernization of Russian education has led to a shift in the target paradigm: from the qualification characteristic of training specialists to a competent approach in higher school. European documents contain definitions of the main concepts of "competence" and "competence." Competence refers to a motivated ability to do anything well or effectively, a potential opportunity for something. Competence is the "use of knowledge - competence in action," that is, a situational category characterizing an individual 's willingness to perform activities in specific professional situations. It can be argued that the concept of "competence" is broader than "competence," as it is a personal quality enhanced by an activity basis (Documents of the Council of Europe, 2014).

In 31.05.01 «THE MEDICAL TREATMENT» (specialist programme level) determines by FGOS requirements to results of development of the program (Section $\mathrm{V}$ ) by the direction of preparation and indicates that they at the graduate have to be created common cultural (OK), all-professional (OPK) and the professional competences (PC) (Order of Ministry of education and science of the Russian Federation of February 9, 2016).

Among the general cultural competences (section 5.2), which should be held by a graduate who has learned the program of specialization, we highlight "readiness to work in a collective, tolerance of social, ethnic, confessional and cultural differences" (OK-8). The formation of intercultural competences of the future doctor can be realized in continuity and integration with the acquisition of such general professional competences (section 5.3) as: readiness to solve standard tasks of professional activity using information, bibliographic resources, medical and biological terminology, information and communication technologies and taking into account the basic requirements of information security (MIC-1); Readiness to communicate orally and in writing in Russian and foreign languages to solve problems of professional activity (MIC-2); Ability and willingness to implement ethical and deontological principles in professional activities (GCC-4); Readiness for medical use of medicines and other substances and their combinations in solving professional problems (OPK-8). The allocated OPK can be carried to three main groups: use medical (medicobiological, pharmaceutical) terminology, readiness for communication in native and foreign languages, possession of ethic and deontological bases of communication in the medical sphere (Khabibullina, 2019, pp.19-25).

The organization of training of foreign students in the Russian university, who have national-specific experience of educational activity, according to A.I. Surygin, is based on the principles of communicativity, consideration of national-cultural peculiarities and intercultural interaction. The principle of communicativity as the leading methodological principle implies the organization of the educational process in conditions close to natural for communication. It involves the use of real communication situations, organization of 
active creative activity, application of collective forms of work, attention to problem situations and creative types of task involving students in general activity (Surygin, 2000). According to Sheveleva S.I., the principle of taking into account national-cultural peculiarities is due to the specificity of the population of students studying, first of all, at the stage of pre-emptive training and having national-specific experience of learning in the natural environment (Sheveleva, 2010, p.315). This principle is also relevant in the organization of the educational process of students of the first year of study, as the process of adaptation is long-term, shortterm courses of language training are insufficient to overcome the language barrier.

The principle of intercultural interaction implies the organization of an educational process in which the teacher takes into account the national and cultural characteristics of students in the context of intercultural communication with speakers of the language. This principle promotes intercultural competence.

A number of research papers on special aspects of teaching Russian as a foreign language, the languageintermediary of which is English. The authors (M.V. Buevsky, N.V. Goncharenko, O.N. Altukhova and O.P. Ignatenko) propose to use a combination of techniques of conscious-practical and translation methods based on the language-intermediary. This reception is developed in an innovative method of teaching Russian language to students of medical direction using English as an intermediary at the initial stage. The effectiveness of the educational process requires a certain socio-cultural training of teachers when working with this group of students, which is also necessary, as well as the formation of socio-cultural competence among students.

According to modern researchers (Rubina S.N., Filimonov N.Y.), the formation of intercultural communication is carried out taking into account the main components: ethnopsychological, due to the mental characteristics of national cultures; Behavioural, dictated by the national-cultural specificity of communicative behavior; Linguistic, taking into account national-cultural language content. Conditions of successful communication depend on several factors: correct organization of educational process, contact of subjects of educational process, availability of didactic materials, equipping of audiences with the necessary technical equipment for presentation and activation of material, provision of faculties with competent specialists.

The study of the formation of intercultural competences of future doctors by means of Latin language is devoted to a series of articles by authors of this work. These publications show the specifics of teaching the course "Latin Language" in the specialty 31.05.01 "THE MEDICAL TREATMENT» as a necessary resource for the development of intercultural competences in future medical specialists at phonetic, grammatical and lexical levels, and describe the possibilities of using the cultural content of the Taught Discipline Program (Khabibullina, Shestakova, Ivanova, 2018, pp.5-11). One of the authors considers the process of intercultural communication as a necessary aspect of the successful adaptation process of Russian and foreign students. The role of the teacher in building pedagogical communication taking into account the specific intercultural nature of communication between subjects of pedagogical and educational activities is emphasized (Ivanova, 2020, pp.17-21). One of the areas of the study is the study of possibilities of formation of intercultural competences of university students in teaching Latin. In the context of globalization, Latin can act as an integrating factor in regional higher education institutions of Russia when teaching disciplines of humanitarian and natural-scientific profiles. The article on the possibility of implementing a competent approach in the process of teaching Latin in a higher educational institution of medical profile, establishes that the leading aspects in the implementation of this approach in the intercultural training of a future medical specialist are systemicity, dialogue, context, terminology and ethical-deontological orientation (Khabibullina, 2017, pp.58-63; Khabibullina, 2020, pp.6-16).

\section{DISCUSSIONAND RESULTS}

The study of theoretical material and experience of pedagogical activity in the Russian regional university show that the organization of intercultural education is based on the principles of communicativity, consideration of national-cultural peculiarities and intercultural interaction of subjects of the educational process. The principle of communicativity as the leading methodological principle implies the organization of the educational process in conditions close to natural for communication, the use of situations close to real professional communication, the application of collective forms of work, the emphasis of attention on problem situations of an intercultural nature. The principle of taking into account national-cultural peculiarities is due to the specificity of the multilingual and multicultural population of students of the modern regional university, who have national-specific experience of study and communication in the natural environment. The principle of intercultural interaction implies the organization of an educational process in which the teacher takes into account the national and cultural characteristics of students in the context of intercultural communication with speakers of the language. 
Intercultural communication is formed taking into account the main components: ethnopsychological, driven by the mental characteristics of national cultures; Behavioural, dictated by the national-cultural specificity of communicative behavior; Linguistic, taking into account national-cultural language content.

Conditions of successful communication depend on several factors: correct organization of educational process, contact of subjects of educational process, availability of didactic materials, equipping of audiences with the necessary technical equipment for presentation and activation of material, provision of faculties with competent specialists. The effectiveness of the educational process requires a certain socio-cultural training of teachers when working with this group of students, which is also necessary, as well as the formation of socio-cultural competence among students. Pedagogical communication is mainly realized during classroom classes. Communication between subjects of the training process is built by means of conditional speech situations. A systemic component of situations is the relationship between Communists, the main factors of which are the role of the participant in the process as a subject of communication and its activities.

The main communicative skills of teachers are: the ability to contact under any conditions, even without knowledge of the language-intermediary; The ability to influence a foreign audience depending on its national composition; The ability to organize scientific and creative activities of students, preventing intercultural and other conflicts in the audience; The ability to compare different cultural traditions, namely, to be aware of the peculiarities of their culture compared to that of trainees.

Language is seen as an instrument and component of culture. However, language is an autonomous entity to relate to culture as a whole and is seen as an autonomous semiotic system. Universality, which is one of the main features of language, allows for intracultural and intercultural communication. These functions find realization in the study of English-speaking students of the Faculty of Medicine of Latin in terms of accessibility in the understanding of terms due to their international nature.

Latin refers to the disciplines of the humanitarian cycle that teach a student to think scientifically using concepts of a chosen specialty. This subject creates the basis of scientific knowledge, thus helping to learn in the specialty. It provides opportunities for the formation and development of professional speech, contributes to the performance of communication tasks of the future medical worker, and performs interlanguage professional communication. Knowledge of Latin makes it easier to read foreign-language, professionally oriented texts filled with international terminology of medical topics. For example, names of anatomical and clinical terminology, methods of examination and treatment in all European languages are framed through Greco-Latin terminology. This phenomenon leads to the unification of medical terminology, which promotes intercultural communication in the field of medicine. The problem of the mastery of Romanisms is important for determining the terminology criteria of a language sign in a system of medical terms. Latin, which was a special language of science in Western European countries during a certain historical period, influenced the formation of national languages in general and medical medicine in particular.

The comparative-comparative approach is leading in the memorization of Greek-Latin term elements, which are the basis of the word formation of terms of medical meaning. It is important that the ancient terminological heritage laid the foundation for the international terminological fund, the Greco-Latin wordbuilding elements have acquired the status of international term elements. In clinical terminology, there is a particular influence of Greco-Latin term elements on the dictionary and word-formation fund of English. The motivation of most medical terms is due to the presence of Latin and Greek word-forming elements translated or borrowed from foreign-language sources.

The teaching of pharmaceutical terminology is based on a comparison of two languages and is simplified by internationalism, as the list of Latin names of drugs and forms constitutes the International Pharmaceutical Nomenclature. This section includes the extraction of frequency segments containing certain standard information about the drug in the drug names. As a rule, in pharmaceutical terminology, drug names are formed precisely by combining standard frequency segments for the whole world.

The Latin language course has a rich cultural content. The Programme's socio-cultural (country) information includes the following elements:

Information of an encyclopedia nature (history, periods of development of ancient Roman civilization, geography, stages of development of Latin language, system of medical and health-improving state and public institutions of the Ancient World, etc.);

- Monuments of material and intangible culture (medical symbols, mythological stories of medical topics and characters in literature and sculpture, etymology of anatomical terms, phytonyms); 
- Name of outstanding personalities, famous Greek and Roman doctors;

- A corps of Latin popular expressions and medical sentences.

The development of Latin medical terms and term elements by national languages is due to the development in Romanisms of paradigm (hierarchical, variant, synonymous, antonical) relations, as well as synthagmatic relations, for example, linear combination of term elements of different genesis.

In the course of classes it is recommended to use mainly methods and techniques of interactive technologies, which contribute to formation of adequate position in intercultural interaction: captives "for and against," intercultural training, work with texts of intercultural orientation (stage "Challenge." "Reflection of cultural material," Inclusion of cultural information in situational and communicative activities, "Reflection"), cultural-oriented tasks (search-game tasks, direction to identify similarities and differences of foreignlanguage and native cultures, game-discussion, role-playing games, problem-communicative tasks).

\section{CONCLUSIONS}

Academic mobility of students, integration of educational systems and institutions of countries, interstate partnership in the field of vocational training of students - a typical landscape of modern educational space.

An intercultural approach is the most appropriate for student learning, as in a global internationalization, a future professional needs to take into account intercultural differences and cultural commonalities to choose the style, strategies and tactics of communication in cross-cultural business situations.

The question of reorienting students 'language education towards an intercultural approach should be raised and addressed. It will allow to realize modern needs in transformation of competent models of the student of the regional university of medical profile, mastering the language not for the sake of communication, and not even for the sake of understanding of culture. Language in this case becomes an instrument of dialogue of (professional) cultures and an effective tool for realization of all professional communicative intences of the specialist related to interaction with colleagues - representatives of another culture, country, another society.

Thus, the study of Latin is an integral part of the training of future doctors. The program of the course "Latin Language" contains the necessary material to create the basis of the terminology system of professional language for Russian and foreign students studying in the multi-language and multicultural space of the Russian regional university. This is facilitated by the fact that medical vocabulary and professional thesaurus of doctors of Latin origin have the greatest specific weight in the system of training of specialists.

\section{REFERENCE LIST}

Documents of the Council of Europe. (2014). URL: http://tuningacademy.org/wpcontent/uploads/2014/02/TuningEUI Final-Report EN.)

Ivanova I.G. (2020). Formation of the Basics of Intercultural Communicationof Foreign Students in a University Setting.Yoshkar-Ola. Pp. 17-21

Khabibullina F. Ya. (2019). Competence-based Approach to Intercultural Training of a Future Specialist Medical Profile by Means of the Latin Language. Yoshkar-Ola. Pp. 19-25.

Khabibullina F. Ya.,Shestakova O. B.,Ivanova I. G. (2018). The Intercultural Aspect of the Program of the Discipline «Latin Language» for Foreign Students on Specialty «The Medical Treatment».YoshkarOla. Pp. 5-11.

Khabibullina F.Ya. (2017). Using the possibilities of learning Latin as an integrating element in the conditions of an intercultural environment of a regional Russian University. Yoshkar-Ola. Pp. 58-63.

Khabibullina F.Ya. (2020). Internationalization of Higher Education as a Factor in the Development of Cross-Cultural Competencies. Yoshkar-Ola. Pp. 6-16.

Order of Ministry of education and science of the Russian Federation of February 9, 2016 N95 about the approval of the Federal state educational standard of higher education in the field of training 31.05.01 Medical business (specialty level). (2016). URL: http://fgosvo.ru/news/21/1807

Sheveleva S.I. (2010). Features of the organization of the educational process in the Russian language as a 
Proceedings of SOCIOINT 2020- 7th International Conference on Education and Education of Social Sciences, 15-17 June 2020

foreign language, taking into account the national specifics of students. Young scientist. 10. Pp. 314316.

Surygin A.I. (2000). Fundamentals of the theory of teaching in a non-native language for students. St. Petersburg. $225 \mathrm{p}$ 